\title{
Prevalence and patterns of drug resistance among pulmonary tuberculosis patients in Hangzhou, China
}

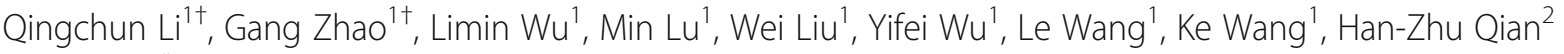
and Li Xie ${ }^{1 *}$

\begin{abstract}
Background: To evaluate prevalence and patterns of drug resistance among pulmonary tuberculosis (TB) patients in Hangzhou City, China.

Methods: Sputum samples of smear positive TB patients enrolled in 2011 and 2015 were collected and tested for drug susceptibility, and demographic and medical record data were extracted from the electronic database of China Information System for Disease Control and Prevention. Chi-square test was used to compare drug resistance prevalence between new and treated patients and between male and female patients, and Chi-square test for trend was used to compare the prevalence over calendar years 2011 and 2015.

Results: Of 1326 patients enrolled in 2015, 22.3\% had resistance to any first-line anti-TB drugs and 8.0\% had multi-drug resistance (MDR); drug resistance rates among previously treated cases were significantly higher than among new cases. Significant declines of resistance to isoniazid, rifampin, ethambutol and streptomycin, and MDR from 2011 to 2015 were observed among previously treated patients, while a significant decline of resistance to rifampin was observed among new cases.

Conclusions: While the prevalence of acquired drug resistance decreased due to due to implementation of DOTS-Plus program, the prevalence of primary drug resistance due to transmission remained high. Greater efforts should be made to screen drug resistance for case finding and to reduce transmission through improving the treatment and management of drug-resistant patients.
\end{abstract}

Keywords: Tuberculosis, Drug sensitivity testing, Drug resistance, China

\section{Background}

China is one of the countries with the highest burden of tuberculosis (TB) disease in the world. Although its ranking in total TB cases dropped in 2015 from second to third behind India and Indonesia [1], the epidemic of drug-resistant TB (DR-TB) and multi-drug resistant TB (MDR-TB) is still a severe public health issue in China. A national survey published in 2012 showed 5.7\% of new cases and $25.6 \%$ of previously treated cases had MDR-TB, both higher than the global averages [2]. The

\footnotetext{
* Correspondence: jiefangsuo@sina.com

${ }^{\dagger}$ Equal contributors

${ }^{1}$ Hangzhou Center for Disease Control and Prevention, Mingshi Road,

Hangzhou City 310021, Zhejiang Province, China

Full list of author information is available at the end of the article
}

prevalence of DR-TB and MDR-TB varied geographically, and 57\% TB patients were resistant to any first-line drugs and $24.1 \%$ were resistant to multiple drugs in high-burden regions [3, 4]. Studies have been conducted to investigate the prevalence of $\mathrm{TB}$ drug resistance across the country in recent years $[3,5]$, but few have evaluated the temporal trend. A study in Shanghai City in the middle of China's east coast found the drug resistance rates increased significantly from 2000 to 2003, and then stabilized during 2004-2006 [6]. A study among TB patients in Hangzhou City in east China showed DRTB and MDR-TB prevalence was $31.3 \%$ and $11.6 \%$, respectively [7]. Little is known about the patterns of drug resistance and recent trend of the epidemic in Hangzhou City. This study reports drug resistance patterns and the

(c) The Author(s). 2018 Open Access This article is distributed under the terms of the Creative Commons Attribution 4.0 International License (http://creativecommons.org/licenses/by/4.0/), which permits unrestricted use, distribution, and reproduction in any medium, provided you give appropriate credit to the original author(s) and the source, provide a link to the Creative Commons license, and indicate if changes were made. The Creative Commons Public Domain Dedication waiver (http://creativecommons.org/publicdomain/zero/1.0/) applies to the data made available in this article, unless otherwise stated. 
epidemic trend from 2011 to 2015 in Hangzhou City in eastern China.

\section{Methods}

\section{Study population}

Hangzhou City is located in eastern China, about a hundred miles away from Shanghai. It comprises 13 districts, one county-level city, and two counties, and has 7.2 million local residents and over 2 million migrant populations.

All smear-positive pulmonary TB patients who lived in Hangzhou in years 2011 and 2015 were included in this study. The highest value was used for analysis if patients had multiple drug susceptibility testing (DST) results in the study years.

\section{Data collection and bacteriologic examinations}

TB is a notifiable disease in China. Over 68,000 health facilities report notifiable diseases to the national, real-time, internet-based disease reporting system, known as the China Information System for Disease Control and Prevention (CIS-DCP). Hangzhou City Center for Disease Control and Prevention (CDC) is authorized for access to the sociodemographic information and medical records of TB patients who live in Hangzhou in this system.

TB cases were diagnosed following Chinese clinical guideline for TB diagnosis and treatment. Three sputum samples were collected from each participant at different time points (clinic visit, early morning, and night) prior to initiation of treatment, and were examined for acidfast bacilli (AFB). Two specimens with the highest bacterial counts were used for culture. TB culture was performed as follows: First, decontaminating and digesting the sputum with equal volume of $4 \%$ sodium hydroxide for $15 \mathrm{~min}$; Then, inoculating $0.1 \mathrm{ml}$ specimen into the Lowenstein-Jensen medium, and culturing it in incubator at $37{ }^{\circ} \mathrm{C}$; After that, observing the colony growth, which was confirmed by microscopic examination for AFB through Ziehl-Neelsen staining.

Species identification of mycobacteria was performed by conventional biochemical tests. Drug sensitivity test was performed using the proportion method on Löwenstein-Jensen medium, with the following concentrations: 0.2 micrograms per milliliter $(\mu \mathrm{g} / \mathrm{ml})$ for isoniazid, 2 . $0 \mu \mathrm{g} / \mathrm{ml}$ for ethambutol, $2.0 \mu \mathrm{g} / \mathrm{ml}$ for ofloxacin, $4.0 \mu \mathrm{g} /$ $\mathrm{ml}$ for streptomycin, $30 \mu \mathrm{g} / \mathrm{ml}$ for kanamycin, and $40 \mu \mathrm{g} / \mathrm{ml}$ for rifampin. The critical growth proportion for drug resistance was $1 \%$ for all drugs. All drugs were obtained from Sigma Life Science Company (USA). The standard sensitive strain $\mathrm{H} 37 \mathrm{Rv}$ was tested in each set of the tests and again within each set if the batch of medium was changed. The drug sensitivity test result or the H37Rv should be sensitive. All drug sensitivity tests in years 2011 and 2015 were performed by the same staff in the TB reference laboratory at Hangzhou CDC, a part of World Health Organization/International Union against Tuberculosis and Lung Disease Global Project on AntiTuberculosis Drug Resistance Surveillance.

\section{Statistical analysis}

Statistical analysis was conducted with SPSS 12.0 software. Chi-square tests or Fisher's exact tests were used comparing drug resistance rates between new and treated patients and between male and female patients. Chi-square tests for trend were used for comparing the difference of drug resistance rates from 2011 to 2015. $P$ value $<0.05$ was considered statistically significant.

\section{Results}

\section{Demographic characteristics of TB patients}

The general characteristics and drug resistance rates of 1184 participants in 2011 were reported elsewhere [7]; of these participants, 903 (76.3\%) were new TB patients and $281(23.7 \%)$ were previously treated patients. In 2015, a total of 1888 smear-positive pulmonary TB patients who lived in Hangzhou were diagnosed, of whom 1583 (83.8\%) had positive sputum culture results and 1332 (70.6\%) were positive for M. tuberculosis. Six patients were excluded due to lack of drug sensitivity test results for first-line anti-TB drugs; therefore, 1326 (70. $2 \%)$ patients were included in the analysis.

Of 1326 patients, 961 (72.5\%) were male and 365 (27. 5\%) were female; 1305 (98.42\%) were Han Chinese and 21 (1.58\%) were other ethnic minorities; age ranged from 12 to 94 years (mean 54); 289 (21.8\%) were migrants; 1020 (76.9\%) were new cases and 306 (23.1\%) were previously treated cases; 874 (65.9\%) had a drug sensitivity test result for ofloxacin and 875 (66.0\%) for kanamycin.

\section{TB drug resistance patterns in 2015}

In 2015 , about $18 \%(184 / 1020)$ new TB patients were resistant to at least one first-line drug, while the prevalence of drug resistance among previously treated patients was double $(36.6 \%, 112 / 306)$ (Table 1$)$. The majority of drug resistance cases had resistance to a single drug, such as streptomycin, isoniazid, rifampin, ofloxacin, ethambutol and kanamycin. Eight percent of TB patients had multi-drug resistance (MDR), 3.8\% among new patients and $22.2 \%$ among previously treated patients; the common combinations of MDR were isoniazid with rifampin or streptomycin. One new patient and two previously treated patients had extensive drug resistance (XDR) (Table 1).

The difference in the prevalence of resistance to any single drug or to multiple drugs between new and treated patients was statistically significant (Table 2). This difference was same for both male and female patients, separately (not shown in tables). There was no statistically significant difference of drug resistance prevalence between male and 
Table 1 Drug resistance patterns among 1326 tuberculosis patients in Hangzhou, China, 2015

\begin{tabular}{|c|c|c|c|c|}
\hline \multirow[t]{2}{*}{ Type of TB resistance } & \multicolumn{2}{|c|}{$\begin{array}{l}\text { New cases } \\
(N=1020)\end{array}$} & \multicolumn{2}{|c|}{$\begin{array}{l}\text { Treated cases } \\
(N=306)\end{array}$} \\
\hline & $\mathrm{n}$ & $\%$ & $\mathrm{n}$ & $\%$ \\
\hline Resistance to any first-line drugs & 184 & 18.0 & 112 & 36.6 \\
\hline \multicolumn{5}{|l|}{$\begin{array}{l}\text { Resistance to individual drugs } \\
\text { in any tests }\end{array}$} \\
\hline Isoniazid & 102 & 10.0 & 89 & 29.1 \\
\hline Rifampin & 57 & 5.6 & 78 & 25.5 \\
\hline Ethambutol & 15 & 1.5 & 23 & 7.5 \\
\hline Streptomycin & 119 & 11.7 & 58 & 19.0 \\
\hline Ofloxacin & 20 & 2.0 & 15 & 4.9 \\
\hline Kanamycin & 7 & 0.7 & 4 & 1.3 \\
\hline \multicolumn{5}{|l|}{ Resistance to single drug only } \\
\hline Isoniazid & 33 & 3.2 & 15 & 4.9 \\
\hline Rifampin & 15 & 1.5 & 8 & 2.6 \\
\hline Ethambutol & 2 & 0.2 & 0 & 0 \\
\hline Streptomycin & 57 & 5.6 & 10 & 3.3 \\
\hline Ofloxacin & 14 & 1.4 & 3 & 1.0 \\
\hline Kanamycin & 2 & 0.2 & 0 & 0 \\
\hline \multicolumn{5}{|l|}{ Resistance to two drugs } \\
\hline Isoniazid+ethambutol & 1 & 0.1 & 1 & 0.3 \\
\hline Isoniazid+streptomycin & 27 & 2.7 & 3 & 1.0 \\
\hline Rifampin+ethambutol & 1 & 0.1 & 0 & 0 \\
\hline Rifampin+streptomycin & 3 & 0.3 & 1 & 0.3 \\
\hline Ethambutol+streptomycin & 1 & 0.1 & 1 & 0.3 \\
\hline Rifampin+ofloxacin & 0 & 0 & 1 & 0.3 \\
\hline Streptomycin+ofloxacin & 2 & 0.2 & 1 & 0.3 \\
\hline Isoniazid+ofloxacin & 1 & 0.1 & 1 & 0.3 \\
\hline Streptomycin+ kanamycin & 1 & 0.1 & 0 & 0 \\
\hline Isoniazid+rifampin & 9 & 0.9 & 19 & 6.2 \\
\hline \multicolumn{5}{|l|}{ Resistance to three drugs } \\
\hline Isoniazid+rifampin+ethambutol & 0 & 0 & 6 & 2.0 \\
\hline Isoniazid+rifampin+Streptomycin & 16 & 1.6 & 24 & 7.8 \\
\hline Ethambutol+streptomycin+ofloxacin & 0 & 0 & 1 & 0.3 \\
\hline Isoniazid+rifampin+ofloxacin & 1 & 0.1 & 1 & 0.3 \\
\hline Isoniazid+rifampin+kanamycin & 1 & 0.1 & 0 & 0 \\
\hline Isoniazid+ethambutol+ofloxacin & 0 & 0 & 1 & 0.3 \\
\hline \multicolumn{5}{|l|}{ Resistance to four drugs } \\
\hline $\begin{array}{l}\text { Isoniazid+rifampin+ethambutol } \\
\text { +streptomycin }\end{array}$ & 8 & 0.8 & 10 & 3.3 \\
\hline $\begin{array}{l}\text { Isoniazid+rifampin+ethambutol } \\
\text { +ofloxacin }\end{array}$ & 0 & 0 & 2 & 0.7 \\
\hline $\begin{array}{l}\text { Isoniazid+rifampin+streptomycin } \\
\text { +ofloxacin }\end{array}$ & 1 & 0.1 & 1 & 0.3 \\
\hline $\begin{array}{l}\text { Isoniazid+rifampin+streptomycin } \\
\text { +kanamycin }\end{array}$ & 0 & 0 & 2 & 0.7 \\
\hline
\end{tabular}

Table 1 Drug resistance patterns among 1326 tuberculosis patients in Hangzhou, China, 2015 (Continued)

\begin{tabular}{|c|c|c|c|c|}
\hline \multirow[t]{2}{*}{ Type of TB resistance } & \multicolumn{2}{|c|}{$\begin{array}{l}\text { New cases } \\
(N=1020)\end{array}$} & \multicolumn{2}{|c|}{$\begin{array}{l}\text { Treated cases } \\
(N=306)\end{array}$} \\
\hline & $n$ & $\%$ & $\mathrm{n}$ & $\%$ \\
\hline \multicolumn{5}{|l|}{ Resistance to five drugs } \\
\hline $\begin{array}{l}\text { Isoniazid+rifampin+ethambutol } \\
\text { +streptomycin+ofloxacin }\end{array}$ & 0 & 0 & 2 & 0.7 \\
\hline $\begin{array}{l}\text { Isoniazid+rifampin+ethambutol } \\
\text { +streptomycin+kanamycin }\end{array}$ & 1 & 0.1 & 0 & 0 \\
\hline Multi-drug resistance (MDR) & 38 & 3.7 & 68 & 22.2 \\
\hline \multicolumn{5}{|l|}{ Extensive drug resistance (XDR) } \\
\hline $\begin{array}{l}\text { Isoniazid+rifampin+ofloxacin } \\
\text { +kanamycin (or cycloserine) }\end{array}$ & 1 & 0.1 & 2 & 0.7 \\
\hline
\end{tabular}

female participants, and no difference by age group (not shown in tables).

\section{Time trend of drug resistance from 2011 to 2015}

A significant decline of resistance to any first-line drugs from 2011 to 2015 was observed: from $31.3 \%$ to $22.3 \%$ among all TB patients, and from $23.4 \%$ to $18 \%$ in new and $57 \%$ to $36.6 \%$ in previously treated patients $(P<0$. $01)$. There were significant declines in resistance to isoniazid, rifampin, ethambutol, streptomycin, and multidrugs among previously treated patients, while among new patients there was a significant decline for rifampin only (Table 3 ).

\section{Discussion}

Our study showed that $22.3 \%$ of TB patients in Hangzhou City in 2015 were resistant to at least one first-line anti-TB drugs and $8.0 \%$ were MDR, and the prevalence of MDR was lower among new cases (3.7\%) than among treated cases $(22.2 \%)$. The MDR prevalence is comparable to the global average, e.g., 3.3\% among new cases and 20\% among previously treated cases [1]. Among TB patients in Zhejiang province where Hangzhou City is located, $23.6 \%$ were resistant to any first-line drugs and 5.0\% were MDR [8]. The prevalence rates of any first-line drug resistance and MDR in six Chinese provinces were $23.4 \%$ and $13.5 \%$, respectively [9], whereas in other areas, the rate of resistance to any first-line drugs ranged from $16.6 \%$ and $57 \%$, and MDR from $4.0 \%$ to $24.1 \%$ [5, $6,10-13]$. In summary, the drug resistance prevalence in Hangzhou City was in the lower range of the epidemics in China.

Studies have shown that there is increasing or persistently high prevalence of drug resistance among TB patients in Mainland China $[3,5,6,14]$, a review showed that primary MDR-TB prevalence in China was below 4 . $0 \%$ before 1995 , and reached $10 \%$ by 2005 ; The acquired MDR-TB prevalence increased from 5\% in 1995 to 32. 
Table 2 Comparison of drug resistance among 1326 new and treated tuberculosis cases in Hangzhou, China, 2015

\begin{tabular}{|c|c|c|c|c|c|}
\hline Type of TB resistance & $\begin{array}{l}\text { All }(N=1326) \\
n, \%\end{array}$ & $\begin{array}{l}\text { New cases }(N=1020) \\
n, \%\end{array}$ & $\begin{array}{l}\text { Treated cases }(N=306) \\
\mathrm{n}, \%\end{array}$ & $x^{2}$ & $P$ \\
\hline Resistance to any first-line drugs & $296(22.3)$ & $184(18.0)$ & $112(36.6)$ & 46.8 & $<0.01$ \\
\hline Isoniazid & $191(14.40)$ & $102(10.00)$ & $89(29.08)$ & 69.5 & $<0.01$ \\
\hline Rifampin & $135(10.2 \%)$ & $57(5.6)$ & $78(25.5)$ & 102.0 & $<0.01$ \\
\hline Ethambutol & $38(2.9)$ & $15(1.5)$ & $23(7.5)$ & 30.9 & $<0.01$ \\
\hline Streptomycin & 177(13.4) & $119(11.7)$ & $58(19.0)$ & 10.8 & $<0.01$ \\
\hline Multi-drug resistance (MDR) & $106(8.0)$ & $38(3.8)$ & $68(22.2)$ & 109.5 & $<0.01$ \\
\hline
\end{tabular}

$4 \%$ in 1990 and then stayed around 30\% until 2005 [15]. We observed significant decline of TB drug resistance in Hangzhou City, particularly among previous diagnosed TB patients, and the findings have significant implications. First, primary drug resistance among treatmentnaïve TB patients is caused by transmission; while drug resistance among treated patients can also be acquired due to inappropriate treatment. The decline of resistance to most first-line drugs among treated patients, but only to rifampin among new patients during 2011-2015 suggests that the prevalence of acquired drug resistance (ADR) mutations in treated patients declined, but the prevalence of transmitted drug resistance (TDR) mutations remained high. This decline may be due to the improvement of $\mathrm{TB}$ treatment and management in Hangzhou City, as it has implemented the DOTS Plus program-a DOTS program with components for MDR $\mathrm{TB}$ diagnosis, management, and treatment. A recent study in Shanghai showed the primary resistance due to exogenous reinfection was the major cause of drug resistance among treated TB patients [16], and this observation was also confirmed in other parts of China [17]. Another study found that $60 \%$ MRD patients had primary drug resistance attributable to transmission [18]. It is suggested that more efforts are needed to enhance detection, treatment and management of drug resistant patients, and more effective strategies are needed to prevent and interrupt transmission of drug resistant tuberculosis.

Second, the widely used regimens for both new and treated TB patients in China are two months of isoniazid, rifampicin, pyrazinamide and ethambutol followed by four months of isoniazid and rifampicin (2HRZE/4HR) or two months of isoniazid, rifampicin, pyrazinamide, ethambutol and streptomycin followed by six months of isoniazid and rifampicin (2HRZES/6HR) [19].Previous studies showed that about $90 \%$ TB patients with resistance to rifampin

Table 3 Prevalence trend of drug resistance among tuberculosis patients in Hangzhou, China, from 2011 to 2015

\begin{tabular}{|c|c|c|c|c|c|}
\hline Type of TB resistance & Treatment history & $\begin{array}{l}2011 \\
(N=1184)\end{array}$ & $\begin{array}{l}2015 \\
(N=1326)\end{array}$ & $x^{2}$ & $P$ \\
\hline \multirow[t]{3}{*}{ Resistance to any first-line drugs } & All & $371(31.3)$ & $296(22.3)$ & 26.0 & $<0.01$ \\
\hline & New cases & $211(23.4)$ & $184(18.0)$ & 8.3 & $<0.01$ \\
\hline & Treated cases & $160(57.0)$ & $112(36.6)$ & 24.4 & $<0.01$ \\
\hline \multirow[t]{3}{*}{ Isoniazid } & All & $231(19.5)$ & $191(14.4)$ & 11.7 & $<0.01$ \\
\hline & New cases & $103(11.4)$ & $102(10.0)$ & 1.0 & 0.32 \\
\hline & Treated cases & $128(45.6)$ & $89(29.1)$ & 17.1 & $<0.01$ \\
\hline \multirow[t]{3}{*}{ Rifampin } & All & $201(17.0)$ & $135(10.2)$ & 24.9 & $<0.01$ \\
\hline & New cases & $82(9.1)$ & $57(5.6)$ & 8.7 & $<0.01$ \\
\hline & Treated cases & $119(42.4)$ & $78(25.5)$ & 18.7 & $<0.01$ \\
\hline \multirow[t]{3}{*}{ Ethambutol } & All & $60(5.1)$ & $38(2.9)$ & 8.1 & $<0.01$ \\
\hline & New cases & $13(1.4)$ & $15(1.5)$ & 0.0 & 0.95 \\
\hline & Treated cases & $47(16.7)$ & $23(7.5)$ & 11.8 & $<0.01$ \\
\hline \multirow[t]{3}{*}{ Streptomycin } & All & $203(17.2)$ & $177(13.4)$ & 7.0 & $<0.01$ \\
\hline & New cases & $110(12.2)$ & $119(11.7)$ & 0.1 & 0.73 \\
\hline & Treated cases & $93(33.1)$ & $58(19.0)$ & 15.3 & $<0.01$ \\
\hline \multirow[t]{3}{*}{ Multi-drug resistance (MDR) } & All & 137 (11.6) & $106(8.0)$ & 9.2 & $<0.01$ \\
\hline & New cases & $37(4.1)$ & $38(3.7)$ & 0.2 & 0.67 \\
\hline & Treated cases & $100(35.6)$ & $68(22.2)$ & 12.8 & $<0.01$ \\
\hline
\end{tabular}


were also resistant to isoniazid, so drug sensitivity test of rifampin could serve as an index for screening MDR [14]. In our study, $78 \%$ patients with resistance to rifampin were MDR. Rifampin resistance is associated with poorer clinical outcomes and requires an increase in duration of therapy. Although the drug resistance was relatively low among the new cases, $37 \%$ of MDR patients and $62 \%$ of patients with resistance to any first-line anti-TB drugs were from the new cases [20]. Therefore, newly diagnosed patients in economically developed areas should be screened for drug resistance prior to initiate TB treatment [20]. The findings are similar to those from a study in Taiwan, which showed that the acquired MDR-TB prevalence was significantly lower after the implementation of the DOTS and DOTSplus programmes, while the primary MDR-TB prevalence remained stable [21]. The time trends of drug resistance prevalence varied geographically. A meta-analysis published in 2017 revealed that the MDR TB prevalence among newly diagnosed in Ethiopia in East Africa was $1.7 \%$ (95\% confidence interval $[\mathrm{CI}], 1.2-2.3 \%)$ and among previously treated TB patients, $14.1 \%$ (95\% CI, 10.9-17.2\%); The overall MDR-TB prevalence showed a stable time trend over the past 10 years [22]. Another meta analysis of the studies conducted in India revealed a worsening trend in DR-TB between the two study decades (decade 1 from 1995 to 2005: 37.7\% [95\% CI, 29. 0-46.4\%] vs decade 2 from 2006 to 2015: 46.1\% [95\% CI, 39.0-53.2\%]); The pooled estimate of MDR-TB resistance was higher in previously treated patients (decade 1: $29.8 \%$ [95\% CI, 20.7-39.0\%]; decade 2: $35.8 \%$ [95\% CI, 29.2-42.4\%]) as compared with the newly diagnosed cases (decade 1: 4.1\% [95\% CI, 2.7-5.6\%]; decade 2: 5.6\% [95\% CI, 3.8-7.4\%]) [23].

Our study has limitations. First, our study sample only included sputum smear-positive TB patients, but other study showed $17 \%$ of drug-resistant and $20 \%$ of MDR cases were linked to sputum smear-negative sources [24]. Therefore, the prevalence of drug resistance in our study may be overestimated, and our study findings may not be extrapolated to sputum smear-negative TB cases. Second, we did not do genotyping of TB infections, so we were unable to ascertain the sources of drugresistant strains among previously treated cases. Third, we did not perform drug sensitivity testing for secondline anti-TB drugs for all MDR patients, the estimations of resistance to second-line anti-TB drugs and extensive drug resistance might be biased.

\section{Conclusions}

In summary, our study found higher prevalence of drug resistance and MDR among treated $\mathrm{TB}$ patients than among new patients in Hangzhou City, and showed a decreasing trend from years 2011-2015. DOTS-Plus program should be expanded, and greater efforts should be made to screen drug resistance for case finding and to reduce transmission through improving the treatment and management of drug-resistant patients.

\begin{abstract}
Abbreviations
AFB: acid-fast bacilli; CDC: Center for Disease Control and Prevention; CISDCP: System for Disease Control and Prevention; DR-TB: drug-resistant TB; DST: drug susceptibility testing; MDR: multi-drug resistance; TB: tuberculosis; XDR: extensive drug resistance
\end{abstract}

Funding

This study was supported by a grant from Zhejiang Medical and Health Science and Technology Program (2015KYA189).

\section{Availability of data and materials}

According to Chinese law, the public health data are not publicly available, but are available on reasonable requests from the corresponding author.

\section{Authors' contributions}

LQC and ZG equality contributed in study design, data collection, analysis and manuscript writing. WLM, LM, WL, WK participated in study design and data collection; LW and WYF conducted laboratory testing; HZQ revised the manuscript; XL and HZQ participated in study design, data analysis and funding support. All the authors have read the manuscript and have approved it.

\section{Ethics approval and consent to participate}

The study was approved by the ethics committee of Hangzhou City Center for Disease Control and Prevention.

\section{Consent for publication}

All authors have reviewed and approved the manuscript for publication.

\section{Competing interests}

All authors declare that they have no competing interests.

\section{Publisher's Note}

Springer Nature remains neutral with regard to jurisdictional claims in published maps and institutional affiliations.

\section{Author details}

${ }^{1}$ Hangzhou Center for Disease Control and Prevention, Mingshi Road, Hangzhou City 310021, Zhejiang Province, China. ${ }^{2}$ Department of Biostatistics, Yale School of Public Health, New Haven, Connecticut, USA.

Received: 16 January 2018 Accepted: 16 April 2018

Published online: 02 May 2018

\section{References}

1. World Health Organization. Global Tuberculosis Report 2016. Available at http://www.who.int/tb/publications/global_report/en/. Accessed 3 Nov 2017.

2. Zhao $Y L, X u S F$, Wang LX, et al. National survey of drug-resistant tuberculosis in China. New Engl J Med. 2012;366:2161-70.

3. Li D, Wang JL, Ji BY, et al. Persistently high prevalence of primary resistance and multidrug resistance of tuberculosis in Heilongjiang Province, China. BMC Infect Dis. 2016;16:516.

4. Liu BB, Hu PL, Gong DF, et al. Profile and influencing factors of drug resistance of Mycobacterium tuberculosis in smear-positive pulmonary tuberculosis patients in Hunan province. Chin J. Infect Control. 2016; 15(2):73-8.

5. He XC, Zhang XX, Zhao JN, et al. Epidemiological trends of drug-resistant tuberculosis in China from 2007 to 2014. Medicine. 2016:95(15):1-7.

6. Shen $X$, DeRiemer $K$, Yuan ZA, et al. Drug resistant tuberculosis in shanghai, China, 2000-2006: prevalence, trends, and risk factors. Int J Tuberc Lung Dis. 2009;13(2):253-9.

7. Li QC, Wu LM, Lu M, et al. Surveillance for tuberculosis drug resistance in Hangzhou, Zhejiang. Disease Surveillance. 2014;29(3):210-4.

8. Chen SH, Wu BB, Liu ZW, et al. An analysis on the epidemic characteristics of tuberculosis drug resistance in Zhejiang province. Pre Med. 2016;28(8): 757-65. 
9. Song Y, Wan L, Chen SS, et al. Analysis on drug resistance of Mycobacterium tuberculosis and influencing factors in six provinces of China. Chinese Chin J Epidemio. 2016;37(7):945-8.

10. Xi XY, Dai MJ, Yan XB. Drug resistance analysis on Mycobacterium tuberculosis of 2695 sputum smear-positive patients with tuberculosis in Xuzhou area. Chin J Exp Clin Infect Dis (Electronic Edition). 2015;9(3):347-51.

11. Wang $Z \mathrm{D}, \mathrm{Zhang} \mathrm{HQ}$, Ren $\mathrm{ZS}$, et al. Analysis of tuberculosis drug resistance in Qingdao. Chin J Antituberc. 2015;37(6):637-40.

12. Wang $X L$, Wang $X P$, Xiao $H X$, et al. Survey of drug-resistant Mycobacterium tuberculosis in Ningxia. Chin J Tuberc Respir Dis. 2015;38(10):738-40.

13. Wang JJ, Hu Y, Jiang WL, et al. Population-based molecular epidemiologic study of rifampicin-resistant tuberculosis in rural area of eastern China. Chin. J Epidemiol. 2009;30(11):1189-93.

14. Yin QQ, Jiao $W W$, Li QJ, et al. Prevalence and molecular characteristics of drug-resistant Mycobacterium tuberculosis in Beijing, China: 2006 versus 2012. BMC Microbiol. 2016;16:85.

15. Yang XY, Li YP, Mei YW, Yu Y, Xiao J, Luo J, Yang Y, Wu SM. Time and spatial distribution of multidrug-resistant tuberculosis among Chinese people, 1981-2006: a systematic review. Int J Infect Dis. 2010;14(10):e828-37.

16. Nsofor CA, Jiang Q, Wu J, et al. Transmission is a noticeable cause of resistance among treated tuberculosis patients in shanghai, China. Sci Rep. 2017:7:7691

17. Gao Q, Mei J. Transmission is the main cause of high rate of drug-resistant tuberculosis in China. Chin J Antituberc. 2015:37:1091-6.

18. Huai $P$, Huang $X$, Cheng J, et al. Proportions and risk factors of developing multidrug resistance among patients with tuberculosis in China: a population-based case-control study. Microb Drug Resist. 2016;22(8):717-26.

19. National Health and Family Planning Commission of the People's Republic of China. Guideline of tuberculosis control program in China. Beijing. 2008: 57-9.

20. Wang Y. Program of MDR TB control and prevention. Beijing: Military Medicine Science Press; 2012.

21. Chien JY, Lai CC, Tan CK, et al. Decline in rates of acquired multidrugresistant tuberculosis after implementation of the directly observed therapy, short course (DOTS) and DOTS-plus programmes in Taiwan. J Antimicrob Chemoth. 2013;68(8):1910-6.

22. Eshetie S, Gizachew M, Dagnew M, Kumera G, Woldie H, Ambaw F, Tessema B, Moges F. Multidrug resistant tuberculosis in Ethiopian settings and its association with previous history of anti-tuberculosis treatment: a systematic review and meta-analysis. BMC Infect Dis. 2017;17(1):219.

23. Goyal V, Kadam V, Narang P, Singh V. Prevalence of drug-resistant pulmonary tuberculosis in India: systematic review and meta-analysis. BMC Public Health 2017;17(1):817.

24. Yang CG, Shen X, Peng P, et al. Transmission of Mycobacterium tuberculosis in China: a population-based molecular epidemiologic study. Clin Infect Dis. 2015;61:219-27.

\section{Ready to submit your research? Choose BMC and benefit from:}

- fast, convenient online submission

- thorough peer review by experienced researchers in your field

- rapid publication on acceptance

- support for research data, including large and complex data types

- gold Open Access which fosters wider collaboration and increased citations

- maximum visibility for your research: over $100 \mathrm{M}$ website views per year

At BMC, research is always in progress.

Learn more biomedcentral.com/submissions 